\title{
Prospective Science Teachers' Self-Assessments about the Use of Slowmation Approach in Teaching
}

\author{
Erhan Ekici \\ Fatma Ekici \\ Pamukkale University, Faculty of Education, Denizli, TURKEY \\ eekici@pau.edu.tr, fekici@pau.edu.tr
}

\begin{abstract}
In the concept of this study, science teacher candidates prepared some animations regarding biology topics by using slowmotion technique. Following this process of animation making, how teacher candidates see extend of contribution of the process on education is examined. This study is carried out with 49 teacher candidates, who were taking general biology course in the spring semester of 2013-2014 academic years. The data of the research is collected by 8-item five point Likerttype slow-motion survey forms and semi-structured interview questions, developed by the researchers. As a result of the study, the teacher candidates reported that the slow-motion technique is an informative technique, which is instructive, useful, developing their creativity, enjoyable and stimulating to the course. As a result of the interviews made with teacher candidates, it is revealed that they are quite willing to use this technique in their professional lives as a teaching approach, which contribute to their learning skills, thus they want to implement this technique to their students as well.
\end{abstract}

Keywords: slow-motion, teacher candidate, teaching technique, self-assessment

\section{Introduction}

Using technology that is readily accessible can sometimes be a catalyst for such engagement, especially if the tools help pre-service teachers to represent their knowledge in innovative ways (Kim \& Reeves, 2007; Lee, Linn, Varma, \& Liu, 2010). With the rapid advancement in personal digital technologies, it is becoming easier for students such as pre-service teachers to design media products such as animations and videos, which may be a way to support their conceptual understanding of science concepts that are typical in the primary school curriculum (Hoban \& Nielsen, 2012). in several studies involving animations made by experts to assist students in learning science concepts have produced mixed results. Some studies have shown that watching animations to explain science concepts has improved the knowledge of high school and college students (Marbach-Ad, Rotbain, \& Stavy, 2008; Williamson \& Abraham, 1995). But in some studies, contrarily, it has been found that there has been little improvement in learning when students watch animations explaining science concepts (Sanger \& Greenbowe, 2000; Yang, Andre, Greenbowe, \& Tibell, 2003). According to Chan and Black (2005), animations could provide a motivation for engaging with content if learners become the designers and creators rather than consumers of information as in expert generated animations. Although this possibility of motivation for engaging with the content, designing and creating students' own animations have been limited because, this process requires time and sophisticated software and the process is too complex (Hoban \& Nielsen, 2012).

\section{Slowmations}

Slow Motion Animation (abbreviated to "Slowmation") is a new teaching approach that has been developed over the last decade in science education classes at the University of Wollongong. This approach simplifies the complex process of making animations to enable learners to create their own comprehensive animations about science concepts (Hoban, 2005, 2007, 2009; Hoban \& Ferry, 2006). Slowmation technic is similar to clay animation and in this approach, students make research, storyboard, design models, capture digital still images of small manual movements of the models. After these, they use a computer software to play the images in a sequence to simulate movement.

Making a movie using a traditional stop-motion animation technique is feasible, because the creator who manually moves the objects while taking each digital still photograph, thus eliminates the need for complex mechanisms to provide movement. Having pre-service teachers take digital still photos one by one, instead of a continuous 25-30 frames per 
second as in video, also allows them to check, manipulate, think about, discuss and reconfigure the models with each movement and photograph (Hoban \& Nielsen, 2011).

Pre-service teachers can learn the process at the beginning of a course period and can prepare their models made out of daily routine materials such as plasticine, paper, and existing plastic models. If the materials are ready and available, in the course period, they can continue and take digital photos as the models are moved manually. The creation process integrates features of clay animation, object animation and digital storytelling and involves the pre-service teachers in designing and a sequence of representations (Hoban and Nielsen, 2010); (a) research notes, (b) storyboard, (c) models, (d) digital photographs and (e) narrated animation.

In summary, slowmation greatly simplifies the process of creating a stop-motion animation by enabling pre-service teachers to (i) make or use existing 2-D or 3-D models that may lie flat on a table or the floor; (ii) play the animation slowly at 2 frames per second requiring 10 times fewer photos than required in normal animation and (iii) use widely available technology such as a digital still camera, a tripod and free movie-making computer software (Hoban \& Nielsen, 2012). McKnight, Hoban and Nielsen (2011), have explained that a slowmation displays the following features:

- Purpose - the goal of a slowmation is for pre-service teachers to make use of 1-2 minute animated mini-movie to tell a story, and through the creation process, learn about the story's meaning. The design of the slowmation can include a range of technological enhancements such as narration, music, other photos, diagrams, models, labels, questions, static images, repetitions and characters.

- Timing - slowmations are usually played slowly at 2 frames/second, not the usual animation speed of 20-24 frames/second, and thus need ten times fewer photos than in clay or computer animation, hence the name "Slow Animation" or "Slowmation";

- Orientation - models are made in 3D and/or 2D and usually manipulated in the horizontal plane (on the floor or on a table) and photographed by a digital still camera mounted on a tripod looking down or across at the model. This makes the models easier to make, move and photograph;

- Materials - because models do not have to stand up, many different materials can be used such as soft play dough, plasticine, 2D pictures, drawings, written text, existing 3D models, felt, cardboard cut-outs and natural materials such as leaves, rocks or fruit; and,

- Technology - pre-service teachers use their own digital still cameras (with photo quality set on low resolution so as to avoid overloading the editing software) or cameras in mobile phones and free movie-making software available on their computers (e.g. iMovie or SAM Animation on a Mac or Windows Movie Maker on a PC)

\section{Purpose of the Study}

The purpose of this study is to put forward the self-assessments of prospective science teachers about slowmation approach when it is used in science teaching (or learning).

\section{Method}

\section{Participants}

The sample included 49 prospective science teacher in Turkey between the ages of $20-27$ of which $\% 79,6$ were women (n $=39)$, and $20,4 \%$ were men $(n=10)$. The mean age was 21,55 .

\section{Materials}

In this study, a semi-structured interview form was developed and used to investigate pre-service teachers wievs about using slowmations in teaching science. They have already prepared animations related to some biology topics before interviews. The purpose and content of the interview was to put forward their point of view.

Animation Evaluation Form: Pre-service teachers were asked an evaluation to use slowmation preparation approach in teaching science by animation evaluaton form developed by researchers. The form contained 8 items required five ratings. 


\section{Results}

The main aim of this study was to evaluate the wievs of pre-service science teachers about slowmation approach as a teaching method. According to results derived from animation evaluation form, $72 \%$ of pre-service teachers think that this approach helpful in understanding the content. $77 \%$ of them think that slowmation preparation process was enjoyable and $89 \%$ of them think that this process was encouraging. $75 \%$ of pre-service tachers found this process as informative and $83,4 \%$ of them found as helpful in learning. $79,2 \%$ of pre-service teachers think that this process was instructive and $87,4 \%$ of them stated that slowmation preparation process increases the creativity. Nearly all of the participants think that the courses with slowmations will be better than the courses with traditional methods.

In the interviews, participants were asked advantages and disadvantages of using slowmations in teaching science. The responses were summarised in the table below (Table 1). According to results summarized in table 1, participants chiefly emphasized that slowmations provided better and amused learning as advantages. Furthermore, they stated that the approaches facilitated learning and increased creativity. According them, slowmation preparation process provides permanent learning, increases cooperation awareness and technological ability. Furthermore they stated that slowmation increases self-confidence and attendance to lesson.

When disadvantages were asked to the participants, they stated that slowmation requires more time and the process is troublesome. Considering slowmation as waste of time and requiring technological ability are other disadvantages according to pre-service science teachers. Participants stated that slowmation preparation process may be distractive. Some of participants stated that there is not any disadvantages of slowmation preparation process or approaches in teaching science.

\section{Discussion}

According to results, participants considers slowmation approach helpful in understanding science, enjoyable, encouraging, informative, helpful in learning, instructive. According them the process increases creativity. They stated that slowmations provide better and amused or enjoable learning experience and facilitate learning. Furthermore, participants state that the slowmation increase creativity, cooperation, technological ability, self-confidence, attendance to lesson of/for learners. They are advantages of slowmation approach as a teaching learning strategy.

Accorting the pre-service teachers there are also disadvantages of use slowmations. Disadvantages of using slowmation in teaching science are requiring more time, being troublesome, considering as waste of time, tequiring technological ability and other technological requirements such as computers, camera, software.

\section{References}

[1] Chan, M.S., \& Black, J.B. (2005). When can animation improve learning? Some implications for human computer interaction and learning. in P. Kommers \& G. Richards (Eds.), Proceedings of World Conference on Educational Multimedia, Hypermedia and Telecommunications 2005 (pp. 2581-2588). Chesapeake, VA: Association for the Advancement of Computing in Education.

[2] Hoban, G. \& Ferry, B. (2006), Teaching Science Concepts in Higher Education Classes with Slow Motion Animation (Slowmation), Paper presented at the E-Learn, Conference for e learning in higher education, Business Honolulu, Hawaii.

[3] Hoban, G., \& Nielsen,W. (2011). Engaging preservice primary teachers in creating multiple modal representations of science concepts with 'slowmation'. Research in Science Education. doi:10.1007/x11165011-9236-3.

[4] Hoban, G. \& Nielsen, W. (2012): Learning Science through Creating a 'Slowmation': A case study of preservice primary teachers, International Journal of Science Education, DOI:10.1080/09500693.2012.670286

[5] Hoban, G. (2005). From claymation to slowmation: A teaching procedure to develop students' science understandings. Teaching Science: Australian Science Teachers' Journal, 51(2), 26-30.

[6] Hoban, G. (2007). Using slowmation to engage preservice elementary teachers in understanding science content knowledge. Contemporary Issues in Technology and Teacher Education, 7(2), 1-9.

[7] Hoban, G. (2009). Facilitating learner-generated animations with slowmation. in L. Lockyer, S. Bennett, S. Agostino, \& B. Harper (Eds.), Handbook of research on learning design and learning objects: Issues, applications and technologies (pp. 313-330). Hershey, PA: IGI Global. 
[8] Kim, B., \& Reeves, T. (2007). Reframing research on learning with technology: in search of the meaning of cognitive tools. Instructional Science, 35, 207-256.

[9] Lee, H., Linn, M., Varma, K., \& Liu, O. (2010). How do technology-enhanced inquiry science units impact classroom learning? Journal of Research in Science Teaching, 47, 71-90.

[10] Marbach-Ad, G., Rotbain, Y., \& Stavy, R. (2008). Using computer animation and illustration activities to improve high school students' achievement in molecular genetics. Journal of Research in Science Teaching, 45, 273292.

[11] McKnight, A., Hoban, G., \& Nielsen, W. (2011), Using Slowmation for animated storytelling to represent nonAboriginal pre-service teachers' awareness of "relatedness to country", Australasian Journal of Educational Technology, 27(1), 41-54

[12] Sanger, M., \& Greenbowe, T. (2000). Addressing student misconceptions concerning electron flow in aqueous solutions with instruction including computer animations and conceptual change strategies. International Journal of Science Education, 22, 521-537.

[13] Williamson, V., \& Abraham, M. (1995). The effects of computer animation on the particulate mental models of college chemistry students. Journal of Research in Science Teaching, 32, 521-534.

[14] Yang, E., Andre, T., Greenbowe, T., \& Tibell, L. (2003). Spatial ability and the impact of vizualization/animation on learning electrochemistry. International Journal of Science Education, 25, 329-349.

\section{Tables}

Table 1. Advantages and disadvantages of slowmation approaches in teaching science

Advantages
Provides better learning
Provides amused learning
Facilitates learning
Increases creativity
Provides permanent learning
Increases cooperation
Increases technological ability
Increases self-confidence
Increase attendance to lesson
Motivates to learning
Improves observation skill
Provides contact between science and daily life
Students learn to make a research
Improves motor skills
Provides visuality

Disadvantages $f$

42 Requiring more time 22

33 The process is troublesome 19

29 Considered as waste of time 16

15 Requires technological ability 11

12 Causes conflict within the group 7

10 Distraction 5

9 Technological requirements 4

6 Being not easy 2

4 Occurs misconception 2

3 There is no any disadvantage 6 